\title{
Mulheres Unidas com o Brasil: net-ativismo, gênero e amparo
}

\author{
Women United with Brazil: net-activism, gender and protection
}

\section{Mujeres Unidas con Brasil: net-activismo, género y protección}

\author{
José Isaías Venera \\ Universidade da Região de Joinville - SC - Brasil \\ ORCID: https://orcid.org/0000-0002-9220-446X \\ Endereço currículo Plataforma Lattes: http://lattes.cnpq.br/2880751243984719 \\ E-mail: j.i.venera@gmail.com \\ Silvio Simão de Matos \\ Universidade da Região de Joinville - SC - Brasil \\ ORCID: https://orcid.org/0000-0002-0838-0699 \\ Endereço Currículo Plataforma Lattes: http://lattes.cnpq.br/4663610190013516 \\ E-mail: silvio.simon@univille.br \\ Carlos Golembiewski \\ Universidade do Vale do Itajaí - SC - Brasil \\ ORCID: https://orcid.org/0000-0002-5647-6118 \\ Endereço Currículo Plataforma Lattes: http://lattes.cnpq.br/6029341241030720 \\ E-mail: carlosinterligado@yahoo.com.br \\ Louise Carine Bruckheimer \\ Universidade da Região de Joinville - SC - Brasil \\ Endereço Currículo Plataforma Lattes: http://lattes.cnpq.br/1245859618795123 \\ E-mail: louisebru@gmail.com
}

\begin{abstract}
Resumo: Este trabalho é uma análise do grupo fechado no Facebook Mulheres Unidas com o Brasil (MUCB), pela via do net-ativismo, tendo como recorte as discussões de gênero e a noção de (des)amparo na perspectiva da psicanálise. Foram selecionados as postagens e os comentários de um dia de cada uma das semanas em destaque do coletivo MUCB, de 21 de agosto a 25 de outubro de 2019. As discussões sobre net-ativismo estão centradas na teoria de Di Felice (2013), no conceito de gênero baseado em Scott (1990), com seu desdobramento foucaultiano, e na noção de (des)amparo em Freud (1996), a qual é articulada como afeto mobilizador para o ativismo na rede. Nos resultados, percebe-se que o coletivo funciona como uma relação de poder em curso e por ela se formam laços sociais no ativismo em rede.
\end{abstract}

Palavras-chave: Net-ativismo. Subjetividades. Gênero. Amparo. 
Abstract: This work is an analysis of the closed Facebook group Mulheres Unidas com o Brasil (MUCB), through net-activism, focusing on gender discussions and the notion of (un)support from the perspective of psychoanalysis. One day's posts and comments from each of the highlighted weeks of MUCB collective were selected, from August 21 to October 25, 2019. Discussions on net-activism are centered on Di Felice's theory (2013), on the concept of gender from Scott (1990), through a Foucaultian perspective, and on the notion of (un)support by Freud (1996), in which it is articulated as a mobilizing affection for activism in the network. In conclusion, the collective works, among other forms of expression, as an ongoing power relationship and through it social bonds are formed in network activism.

Keywords: Net-activism. Subjectivities. Gender. Protection.

Resumen: Este trabajo es un análisis del grupo cerrado de Facebook Mulheres Unidas com o Brasil (MUCB), por medio del net-activismo, con enfoque en las discusiones de género y la noción de (des)apoyo por la perspectiva del psicoanálisis. Se seleccionaron las publicaciones y los comentarios de un día de cada una de las semanas destacadas del colectivo MUCB, del 21 de agosto al 25 de octubre de 2019. Las discusiones sobre el activismo en red se centran en la teoría de Di Felice (2013), sobre el concepto de género de Scott (1990), con su desenvolvimiento foucaultiano, y en la noción de (des)apoyo en Freud (1996), que se articula como un afecto movilizador por el activismo en la red. Concluyendo, el colectivo funciona, entre otras formas de expresión, como una relación de poder permanente y por ella se forman lazos sociales en el activismo en red.

Palabras clave: Net-activismo. Subjetividades. Género. Protección.

\section{Introdução pela via do net-ativismo}

Em entrevista ao Instituto Humanitas Unisinos, Massimo Di Felice descreve as redes digitais como "uma arquitetura informativa que imita os processos de redes informativas da natureza" (apud ELY, 2018). O sociólogo parte da ideia de "contrato natural" de Michel Serres, que defende um novo modelo de convivência, e da articulação feita por Bruno Latour com a teoria ator-rede. Di Felice evidencia um novo ecossistema com as redes comparando-as com a floresta tropical: "Tudo está conectado, mas tudo se alimenta e se desloca no outro, não existe exterioridade, cada vegetal, cada animal, cada inseto se alimenta da ninfa vital do sangue e da matéria do outro" (apud ELY, 2018). 
Passamos a compreender que habitamos nas redes digitais, fazemos parte delas, nos alimentamos delas e nos constituímos nelas. Assim, estar conectado nas redes digitais não significa uma ação objetiva em que o sujeito consciente interfere no ciberespaço sem ser afetado. As redes ocupam cada vez mais espaço na vida, seja nos serviços que consumimos, seja nos círculos de afetos. As redes integram o nosso ambiente.

Essa afecção produz um sentir híbrido, causado pelas relações entre indivíduos, dispositivos de acesso à internet, plataformas, fluxos informativos, que constituem uma ecologia do sentir. O indivíduo move-se em um ambiente em que:

$\mathrm{Na}$ era das mídias e dos diversos dispositivos eletrônicos, é constituído por uma ecologia de imagens, palavras e sons, com diferentes jogos de linguagem e multiplicação das mediações, das telas e das interfaces que organizam modos de recepção (visual, auditiva, tátil; da sensibilidade, do intelecto e da prática) e modos de uso cada vez mais híbridos, plurais e hipermediáticos (BABO, 2017, p. 82).

Nessa nova ecologia, as mídias conduzem uma hibridização entre espaços sociais e fluxos informativos, como mostra Babo (2017), e que resultam em "meio social reticular". No modelo reticular "a informação navega de forma distributiva, horizontal, dialógica e redundante e onde cada nó tem igual importância e poder de interdependência" (DI FELICE, 2013, p. 55). Esse modelo, o reticular, difere do esquema linear e de causaefeito comum nas teorias da comunicação de massa, entre elas a Escola Funcionalista, com destaque para sua primeira fase, a da manipulação.

As ações não dependem de um lugar nem de uma hierarquia. Nessa nova ecologia a potência está na atopia (sem espaço), a qual se convencionou chamar de espaço virtual, permitindo fluxos informativos entre indivíduos, dispositivos de acesso à rede etc., mas, por meio desse ambiente atópico, mudanças acontecem nas territorialidades, como veremos na atuação do coletivo ${ }^{1}$ Mulheres Unidas pelo Brasil (MUCB).

Um dos pontos centrais da onipresença das redes na vida é a mudança estrutural nos processos de comunicação. O que antes tinha posições fixas - a do emissor e a do receptor -, na rede passa a ser intercambiável. Ao mesmo tempo em que podemos ser observadores (ser receptores) de fluxos comunicacionais, podemos também participar da produção de conteúdo (ser emissores).

\footnotetext{
${ }^{1} \mathrm{O}$ termo coletivo vem ao encontro da noção de agenciamento coletivo de enunciação, conceito de Deleuze e Guattari (1997), para expressar um comum articulado em um movimento de desejo de singularidades. Nesse caso em estudo, as singularidades evidenciam a multiplicidade das formas de ser. 
A mudança no processo comunicacional forma uma nova ecologia e potencializa a configuração de coletivos e ações políticas. A alteração no fluxo comunicacional e a facilidade de acesso às mídias participativas conectadas à internet por meio dos dispositivos móveis (tablet, smartphone etc.) modificaram o cenário das lutas sociais no século XXI, com destaque para as revoluções árabes em 2011 e os protestos de junho de 2013 no Brasil, para citar um período recente já bem demarcado na nossa história.

Di Felice (2013, p. 54) ajuda a compreender essa alteração no fluxo comunicacional e as mudanças nas relações sociais: "Como essa tecnologia transformou substancialmente o próprio ativismo e os conceitos, espaço democrático, identidade coletiva e estratégia política, implicando em uma mudança significativa nas formas de ação social por parte dos movimentos ciberativistas".

Levando-se em consideração as mudanças no processo de comunicação e as novas formas de ativismo que se desenvolvem, o objetivo deste trabalho foi analisar o grupo fechado no Facebook Mulheres Unidas com o Brasil (MUCB), com base nos estudos de net-ativismo, tendo como recorte as discussões de gênero e a noção de (des)amparo. $O$ problema gira em torno do que mobiliza o ativismo em rede e, no plano subjetivo, de que afeto cria essa demanda de formar coletivos.

O MUCB emergiu no período das manifestações populares lideradas por mulheres com o lema \#EleNão, em 2018, em reação aos discursos do então candidato e hoje presidente Jair Bolsonaro. O coletivo, criado em agosto de 2018, é um grupo fechado do Facebook (cuja participação ocorre após a aceitação das administradoras ao clicar em "Participar do grupo"), tendo alcançado, em outubro do mesmo ano, 2,8 milhões de adesões (PELÚCIO; PAZ, 2020). Foi criado, inicialmente, com o nome Mulheres Unidas contra Bolsonaro. No período da pesquisa, em 2019, o coletivo já havia mudado o nome para Mulheres Unidas com o Brasil, mas mais recentemente voltou a ser Mulheres Unidas contra Bolsonaro.

Após um mês de criação do coletivo, a conta do MUCB no Facebook foi hackeada, e as contas pessoais de suas administradoras e moderadoras também foram invadidas ${ }^{2}$.

\footnotetext{
${ }^{2}$ Em matéria da revista Época de 19 de setembro de 2018, na "sexta-feira (14), o telefone da professora Maíra Motta, uma das administradoras do grupo do Facebook Mulheres Unidas contra Bolsonaro, parou de funcionar. Logo em seguida, seu perfil na rede social foi invadido e seus contatos começaram a receber mensagens de ódio pelo WhatsApp. Era o início de uma ação criminosa, com o uso técnico de hacker, que colocou em risco a existência do grupo que reuniu mais de 2 milhões de mulheres em poucos dias" (MATSUURA, 2018). O El País, em 16 de setembro de 2013, informou que os invasores exigiram que o grupo fosse extinto em 24 horas de sexta-feira e tentaram intimidar as responsáveis pelo grupo ameaçando DOI: http://doi.org/10.14393/par-v6n1-2021-61066 - Paradoxos, Uberlândia, v. 6, n. 1, p. 103-123, jan./jun. $2021 \mid 106$
} 
Os hackers definiram-se como apoiadores do então candidato à presidência Jair Bolsonaro, pelo Partido Social Liberal (PSL). Somente em 21 de janeiro de 2019 o coletivo passou a se chamar Mulheres Unidas com o Brasil ${ }^{3}$.

Ganhando corpo, o MUCB criou um site (mucb.com.br), no qual o movimento é apresentado como um coletivo de "mulheres plurais" - deixando assim marcado que há várias formas de viver o feminino. Afirma também que o coletivo é de "resistência" e luta pela "democracia"4.

Tanto no site quanto no Facebook, o MUCB é apresentado como um coletivo de afirmação das várias formas de ser mulher. Outro ponto que se configura como central para este trabalho diz respeito ao círculo de afetos nesse ambiente virtual diante de uma realidade social que nega as várias formas de ser mulher.

\section{Metodologia}

A análise iniciou-se com os estudos de net-ativismo, tendo como recorte o debate de gênero. No segundo momento, foi trazida a noção de desamparo em Sigmund Freud como mobilizador dos coletivos femininos. Na sequência foram analisados os posts e comentários do grupo fechado MUCB no Facebook, no recorte de um dia por semana de 21 de agosto a 25 de outubro de $2019^{5}$, totalizando 10 momentos de análise. Foram investigadas as postagens que apareceram nos dias selecionados, e nem sempre o post em destaque na linha do tempo (timeline) foi publicado no mesmo dia da consulta. Os posts foram salvos mediante a função printscreen e organizados em uma tabela.

Foram 170 posts salvos com os comentários que apareciam em destaque na página do Facebook. Com o recorte do material, desenvolveu-se a análise levandose em conta os posts mais curtidos, com o maior número de comentários e, também, pela natureza do conteúdo, ou seja, com relação aos temas em destaque neste artigo — net-ativismo, gênero e (des)amparo.

divulgar seus dados pessoais como CPF, RG, título de eleitor, nome de mãe, entre outros dados extremamente sensíveis" (EL PAÍS, 2018).

${ }^{3}$ Disponível em: https://www.facebook.com/groups/499414607198716/. Acesso em: 27 dez. 2019.

${ }^{4}$ Disponível em: https://mucb.com.br/. Acesso em: 28 dez. 2019.

${ }^{5}$ Os dias de seleção dos posts mais relevantes, na classificação da própria rede digital, são: 21 , 23 e 30 de agosto; 6, 15, 20 e 27 de setembro; e 4, 18 e 25 de outubro. Nesse recorte, ficou somente um dia da semana entre 6 e 12 de outubro de fora da seleção.

DOI: http://doi.org/10.14393/par-v6n1-2021-61066 - Paradoxos, Uberlândia, v. 6, n. 1, p. 103-123, jan./jun. 2021| 107 
A descrição das ações advém da interação em rede, das conectividades que se formaram, resultando em fluxos informacionais que articulam imagens, audiovisual, textos etc., mas neste trabalho o recorte envolveu apenas os discursos que se apresentam em formato textual.

Nas análises foi citado apenas o primeiro nome das autoras das postagens, preservando, em certa medida, sua identidade. Já nos comentários foi ocultada por completo a autoria.

\section{O gênero como categoria de análise}

O gênero como categoria de análise rompe com a dicotomia sexo e gênero, em que o primeiro termo diz respeito ao biológico e o segundo ao cultural. O gênero enquanto categoria vem no lugar do sexo e "tem uma primeira função ou consequência de rejeitar a imposição por um determinismo biológico sobre o que seria 'ser mulher' e 'ser homem"' (GOMES, 2018, p. 66). Analisar as diferentes posições subjetivas com base na categoria gênero desloca completamente o debate das discussões de natureza, ao mesmo tempo em que abre para as diferentes formas de existir e reivindicar o direito à diferença.

O gênero enquanto categoria de análise teve sua emergência no fim do século XX, como identifica Joan Scott (1990). Para a historiadora, “devemos nos perguntar mais seguidamente como as coisas se passaram para descobrir por que elas se passaram" (SCOTT, 1990, p. 86). O que está em questão é a recusa de uma causalidade universal que explicaria um posicionamento feminino, um "posicionamento baseado no significado". Nessa linha, "para buscar o significado, precisamos lidar com o sujeito individual, bem como a organização social, e articular a natureza de suas interrelações, pois ambos são cruciais para compreender como funciona o gênero, como ocorre sua mudança" (SCOTT, 1990, p. 86). Além desse posicionamento do historiador diante do gênero como categoria, Scott (1990, p. 86) diz que "é preciso substituir a noção de que o poder social é unificado, coerente e centralizado por algo como o poder de Michel Foucault".

No campo da comunicação, podemos também nos apropriar das questões de Scott (1990) unidas com a noção de poder de Foucault (1999), o que nos levará a buscar nas pistas do presente o que se passa para que o poder se manifeste de determinada maneira. Para dizer de outra maneira, o modo como o coletivo de mulheres se articula no grupo 
fechado do Facebook se caracteriza como um poder que se manifesta em relação aos discursos e práticas autoritários, impositivos, que naturalizam as relações sociais.

Em entrevista, Foucault direciona a noção de poder para o que se torna central nesta pesquisa: "Pareceu-me que, enquanto o sujeito humano é colocado em relação de produção e de significação, é igualmente colocado em relações de poder muito complexas" (FOUCAULT, 1985, p. 232). O ponto de interesse sobre a questão do poder é investigar "como se exerce" nas relações que estabelece, de tal maneira que para Foucault deixa a suspeita de que o "poder" não existe fora das relações. O poder estabelece-se em relação, assim como o próprio sujeito se constitui nos processos de subjetivação, e esse sujeito pode também ser compreendido como um sujeito intervalar (VENERA, 2019).

A luta das mulheres no Brasil está ligada, como mostra Cynthia Sarti (2013), com as características da sociedade, fundamentalmente desigual, e, em alguns momentos, com o autoritarismo político, como no período da ditadura militar (1964-1985). Os movimentos das mulheres intensificaram-se no Brasil nesse período autoritário, sobretudo com o impulso que o movimento feminista ganhou quando a Organização das Nações Unidas (ONU) declarou, em 1975, o Ano Internacional das Mulheres. De 1975 a 1985, a ONU instituiu a Década da Mulher. Foi também nos anos de 1970 que ocorreu o aparecimento de importantes periódicos voltados ao tema, como, por exemplo, Brasil Mulher e Nós Mulheres (PEDRO, 2006). A historiadora Joana Pedro (2006, p. 269) vai observar que o jornal Nós Mulheres "passou a ser feito por cerca de vinte mulheres [...]. Proclamavam-se, já no primeiro número, como feministas".

O feminismo no Brasil tem múltiplas faces. Em seu trabalho, Célia Pinto (2003) dedica-se, principalmente, a duas tendências: do fim do século XIX até 1932 e pós-1968 - em síntese, as questões do feminismo “bem-comportado”, primeira tendência, e do "malcomportado", segunda tendência. Nos anos de 1980, o destaque ficou para as organizações não governamentais (ONGs) de mulheres, para abordar as relações entre o campo político e a sociedade organizada. As ONGs abriram "novos espaços públicos de conscientização e construção de opinião, envolvendo populações até então excluídas" (PINTO, 2003, p. 105).

Com a onipresença da internet integrando a vida, novas formas colaborativas permitiram intensificar os ativismos. Este trabalho analisa o ativismo de mulheres contra os discursos, sobretudo, sexistas por meio de ações colaborativas pela internet (net- 
ativismo), buscando também averiguar uma função que integra a constituição psíquica, o (des)amparo, com base nos estudos psicanalíticos iniciados por Freud.

\section{Desamparo: afeto que nos abre para os vínculos}

Em $O$ círculo dos afetos, Safatle (2016, p. 42) apresenta um pressuposto freudiano central: "O afeto que nos abre para os vínculos sociais é o desamparo". Na psicanálise, o desamparo aparece desde os primeiros textos de Freud. Em "Projeto para uma psicologia científica", de 1895, Freud (1990) mostra que o sujeito vive a experiência do desamparo desde seu nascimento. Em "Inibição, sintoma e angústia”, de 1926, ao falar da angústia, entende que ela se revela "produto do desamparo psíquico do bebê, que é a contrapartida evidente de seu desamparo biológico" (FREUD, 2014, p. 80). E em “O futuro de uma ilusão", de 1927, Freud (1996, p. 37) aponta: “A terrível impressão deixada pelo desamparo da criança despertou a necessidade de proteção [...]; e a compreensão de que esse desamparo continua por toda a vida". Resstel (2015, p. 87) explica que, para Freud, "o recém-nascido precisa da ajuda alheia para promover a ação específica de que necessita para sua sobrevivência. [...] O sentimento de desamparo já é sentido pela criança logo ao nascer”.

A experiência com o sentimento de desamparo teria sua origem nessa fase inicial da vida, mas adquire dimensões diferentes na obra de Freud. Safatle (2009) indica três momentos:

1. em direção ao narcisismo primário com seus processos projetivos; 2. posteriormente, à experiência do desamparo com a internalização da Lei social através da constituição de uma instância moral de observação (o supereu); 3. por fim, ao esboço de realização de expectativas emancipatórias (SAFATLE, 2009, p. 360).

Safatle (2009) fez primeiramente uma correlação dessas três fases da obra de Freud com a visão positivista de Auguste Comte. Interessa-nos, sobretudo, essa compreensão do fenômeno, ou seja, que o sentimento de desamparo mobiliza o sujeito a formar laços sociais, o que seria o mesmo que dizer buscar amparo na relação com o outro.

Em entrevista à revista Epos, em 2015, Safatle fala da tese de seu livro $O$ círculo dos afetos, em que procura mostrar "como só as pessoas desamparadas podem agir politicamente" (SAFATLE, 2015, p. 220). A política "é a arte de exigir que sociedades sejam capazes de se relacionar com o que é impróprio, com o que nunca será reduzido à 
condição de propriedade" (SAFATLE, 2015, p. 224). Nesse direcionamento, a política opera sobre o que não está integrado e por meio do qual mobiliza o sujeito à ação.

O coletivo de mulheres que se integra ao grupo fechado no Facebook é uma das formas de reagir perante uma sociedade que cada vez menos ampara suas demandas. $\mathrm{O}$ MUCB constitui-se, assim, como uma política de ativismo em rede (net-ativismo), mas também de busca por amparo, e a origem dessa procura por estabelecer laços sociais decorre da primeira infância, como mostra Freud (1990).

\section{Entre o desamparo e a busca por amparo no MUCB}

O grupo MUCB é resultado das mobilizações ocorridas em 2018 e que ficaram conhecidas como \#EleNão. A organização dos atos de repúdio à candidatura, à época, de Jair Bolsonaro (PSL) surgiu após a repercussão da mobilização integrando as ações do grupo no Facebook Mulheres Unidas contra Bolsonaro.

No plano visível, o MUCB constitui um coletivo que expressa múltiplas formas de ser mulher e por meio do qual são organizadas ações em defesa da democracia, na garantia de direitos constitucionais e na ampliação de novos direitos. Nesta pesquisa, destaca-se uma dimensão subjetiva mobilizada pelo sentimento de desamparo como mecanismo psíquico para a formação do coletivo e das discussões.

Os posts citados neste artigo apareceram em destaque na página do MUCB nos dias selecionados para a pesquisa. Alguns foram publicados um ou dois dias antes da data, mas mantiveram-se em destaque no dia classificado para a pesquisa na qual se realizou a seleção dos posts.

No dia 21 de agosto de 2019, os posts giraram em torno das queimadas na Amazônia, das autorizações para desmatamentos, da luta das mulheres indígenas, da educação e democracia, do caso Marielle Franco e da chamada política de morte do governo Wilson Witzel, do Rio de Janeiro.

Do primeiro post, "O que Bolsonaro tem a ver com as queimadas?", de Monalisa, consta:

Tirando o fato de ter uma política agressiva contra as reservas indígenas, desprezar completamente a Amazônia, justificar o desmatamento, negar o aquecimento global, censurar o órgão que divulga imagens sobre a destruição das florestas, recusar o dinheiro do fundo de manutenção da Amazônia, diminuir a verba para fiscalização, 
estimular madeireiros e fazendeiros e perseguir funcionários do [Instituto Brasileiro do Meio Ambiente e dos Recursos Naturais Renováveis] Ibama, ele não tem culpa nenhuma.

Em tom de ironia, o discurso, ao mesmo tempo em que anuncia o descaso de Bolsonaro com leis de proteção à natureza, aos povos indígenas, aos funcionários públicos e ao aquecimento global, reforça o traço subjetivo que se busca trabalhar nesta análise, o de desamparo. Afeto que sinaliza um estado de vulnerabilidade. Diante desse afeto se formam linhas de forças para enfrentar a realidade. O grupo no Facebook funciona como um dispositivo que permite fluir um circuito de afetos como forma de enfrentamento do afeto de base, o desamparo.

Entre os comentários no post, há: "Até em meio a uma tragédia dessa consegue ser cínico e tratando um assunto tão sério desse com uma risadinha e falta de educação. Estamos lascados mesmo". Na fala, dois pontos podem ser observados: a forma como a internauta qualifica os discursos de Bolsonaro, "cínico", e a reforma do afeto em desamparo: "Estamos lascados mesmos".

O cinismo tem uma estrutura de discurso perversa, diferentemente da ironia, em que sua estrutura é crítica. Para Safatle (2008, p. 22), "o cinismo seria solidário da transformação da perversão, e não mais da neurose, em saldo necessário de nossos processos de socialização". Enquanto na neurose o sofrimento advém da dúvida - o que devo fazer, quem sou, é certo ou errado - , na perversão não há culpa nem problema em ver o outro sofrer. Diante de uma realidade que se apresenta com traços perversos, o afeto desamparo prevalece, fazendo fluir falas como "estamos lascados mesmos".

É também diante de cenários dessa natureza que as mulheres se organizam em coletivos. Como nos fez ver Scott (1990), não há um valor universal que define o comportamento feminino; as várias formas de se viver se associam com as causalidades e com as relações de poder que se formam. O coletivo MUCB, nesse sentido, constituise como uma instância de poder que foi possível por intermédio das interações em rede, consistindo em uma prática de net-ativismo.

Outra internauta comenta: "Acabando com tudo! Triste". Ou seja, acabando com todas as garantias de proteção, de amparo. Na sequência, outro comentário: " $E$ todos continuam calados". Diante de uma realidade perversa por parte daqueles que deveriam fazer a lei se cumprir, contrariamente se calam. Logo, torna-se mais necessária a construção de espaços digitais de agrupamentos, constituindo lugares de fala e de estabelecimento de laços sociais. 
Os laços sociais e as falas que advêm formam o novo ecossistema que Di Felice (2013) apresenta e que alterou substancialmente os ativismos e a própria noção de espaço democrático. No espaço virtual do MUCB, podemos observar práticas discursivas que se formam à luz dos acontecimentos políticos, ao mesmo tempo em que o coletivo de mulheres constrói o processo de conscientização sobre duas práticas.

$\mathrm{Na}$ segunda postagem do dia 21, Fátima compartilha uma matéria do G1, "Governo publica mais de 500 autorizações de desmatamento", a qual é precedida pela frase: "Assassinando a mãe terra". Nos comentários, pode-se observar que o afeto desamparo é o motor dos discursos: "Acabando com tudo! Triste", "E todos continuam calados", "q isso em setembro!!! ate lá nem floresta vai ter gente".

Se as duas primeiras postagens do dia 21 reforçam o descaso das autoridades com as leis e as políticas de proteção do meio ambiente e das pessoas, a terceira postagem, de Cacilda, foi o compartilhamento de um post de Guilherme Boulos, um vídeo de transmissão ao vivo sobre educação e democracia. Na quarta, Laís compartilha uma postagem de Mídia Ninja sobre o discurso da atriz Sônia Braga no 47. ${ }^{\circ}$ Festival de Gramado: "Quero saber: quem matou Marielle". Nos comentários, o que mais foi recorrente: “Também quero!". Na quinta postagem, Ludimilla publica um evento: “Cine debate: auto de resistência".

As postagens seguem nesses dois movimentos: de um lado, expressa eventos de descaso do atual governo federal com a vida - fazendo circular o afeto de desamparo ; e, de outro, ações de fortalecimento do grupo, fazendo circular o afeto de amparo. As ações do MUCB também vão ao encontro das análises de Célia Pinto (2003) sobre as mudanças ocorridas a partir dos anos de 1980, com o fortalecimento das ONGs de mulheres, constituindo-se como um novo espaço de conscientização e construção de opinião. Agora, com os fluxos informáticos em rede, os grupos são um novo espaço de conscientização e construção de opinião.

Entre as postagens do dia 23 de agosto, Isabel compartilha o post do portal Brasil 247 com o título: "Eduardo Bolsonaro insulta Macron, o chama de idiota, e prova que não pode ser embaixador". Em outro post, do mesmo dia, Aurilene compartilha matéria da Central Brasileira de Notícias (CBN): "Pulmões do mundo são os oceanos, não a Amazônia', afirma Mourão". Após essas duas postagens, Carolina publica um evento: “Chega de climão: greve global pelo clima”. Em seguida, Cibele compartilha matéria do portal Brasil 247: "Pimenta quer denunciar Bolsonaro no Tribunal Penal Internacional". 
As postagens seguem na alternância observada no dia 21 de denunciar práticas "perversas" de promoção do desamparo, e, ao contrário, diante das ações políticas as mulheres se mobilizam em ações de amparo. Nos comentários, falas de reforço às denúncias, assim como aos eventos que unem as mulheres.

O fluxo de conteúdo segue os princípios apontados por Isabel Babo (2017, p. 82), constituídos de uma "ecologia de imagens, palavras e sons, com diferentes jogos de linguagem e multiplicação das mediações". É nessa atmosfera potencializada na rede que o coletivo de mulheres dá forma aos seus anseios, defendendo, sobretudo nos posts do dia 23, pautas ecológicas.

Entre as postagens do dia 30 de agosto, Neila compartilha matéria da página da Universidade Federal de Santa Catarina: "Se nada for feito, a Universidade será fechada no final de outubro". No texto que antecede o conteúdo compartilhado:

Triste realidade, universidade Federal de Santa Catarina fechada. Um governo de ignorantes não admite pessoas pensando, querem um Brasil de ignorantes. Assim não será produzida nenhuma pesquisa, nenhuma vacina, nem novos tratamentos, com certeza o Bolsonaro venceu, seremos um Brasil colônia. Que vergonha!

Entre os comentários na postagem: “Quanto desses estudantes aí foram pedir votos para o HOMEM. Tudo volta. Eu não levo essa culpa. LULA LIVRE”, "\#EuAvisei", "A maioria do povo catarinense votou no atual presidente tão reclamando porque", "\#ForaBolsonaro" etc.

A rede funciona também como esse espaço de catarse, meio pelo qual as pessoas expurgam conteúdos incômodos ao mesmo tempo em que sinalizam esperanças, como nos comentários observados, articulando entre eles: "Eu não levo essa culpa" e "Lula livre". Prática que vai ao encontro da descrição de Castells (2003, p. 255), de que a “Internet é o tecido de nossas vidas neste momento. Não é futuro. É presente". A vida tece-se nesses fluxos de conteúdos.

As postagens do dia 30 de agosto seguem com os temas Amazônia, direitos humanos, divulgação de fórum de resistência democrática, racismo, feminicídio, postagens afirmativas de personalidades negras e drag queen. O assunto Amazônia ainda prevalece. Um post de Lucilene compartilha matéria do portal SIC Notícias: "Macron diz que as mulheres brasileiras devem sentir vergonha de Bolsonaro". Nos comentários: "Não só vergonha... mas raiva, desprezo, nojo...", "Sim eu tenho vergonha de ver um cara como este representando uma grande nação. E peço pelo desrespeito com a DOI: http://doi.org/10.14393/par-v6n1-2021-61066 - Paradoxos, Uberlândia, v. 6, n. 1, p. 103-123, jan./jun. $2021 \mid 114$ 
primeira-dama" etc. Os enunciados vergonha, raiva, desprezo, nojo dão o tom do circuito de afetos em torno da tensão diplomática entre Brasil e França com as declarações de Bolsonaro, sobretudo ao comentário sobre a primeira-dama francesa.

A fala de Emmanuel Macron, presidente da França, tema da matéria do SIC Notícias, repercutiu no MUCB em forma de compartilhamento, nesse fluxo de acontecimentos por meio do qual o coletivo de mulheres se posiciona. A objetificação do valor da mulher com base em um padrão de beleza resulta em manifestações de desprezo, como nesse episódio em consequência do comentário de um seguidor na página do Facebook de Bolsonaro, no dia 27 de agosto, inserindo fotos dos dois presidentes acompanhados de suas esposas: "Entende agora pq Macron persegue Bolsonaro?". O comentarista ainda acrescenta: "É inveja presidente do Macron pode crê". O presidente Bolsonaro responde ao comentário: "Rodrigo Andreaça não humilha cara. kkk". Ao responder com alegria ("kkk"), o presidente confirma o posicionamento discursivo do comentário.

Em outra postagem, agora referente à assinatura pelo goleiro Bruno do contrato com o time de futebol Poços de Caldas, há várias falas de indignação, mas nenhum comentário acerca da prática de feminicídio. Bruno foi condenado, em 2010, pelo sequestro e assassinato da modelo Eliza Samudio. Nos comentários prevalecem o enunciado vergonha e a qualificação do goleiro de assassino sem a especificação de que o crime foi contra uma mulher.

Na sequência, Maria compartilha matéria da revista Carta Capital: "Você faz faxina? Não, faço mestrado. Sou professora". Nos comentários, vários relatos de situações de preconceito também pela natureza do trabalho:

Eu passei por uma situação ao contrário. Sou merendeira e como estava numa sala de reuniões num colégio junto com professores $e$ diretores [...] um professor chegou perto de mim e me perguntou se eu era professora de que. ai eu disse: não sou professora, sou merendeira, saiu de perto de mim e nunca mais falou comigo.

As postagens do dia 6 de setembro giram em torno de: "\#EleNão", "Todos de preto no 7 de setembro", o caso Brigitte Macron, relato de maus-tratos em prisões femininas etc. Nessa série de postagens, destacamos o relato de maus-tratos no Centro de Reeducação Feminino (CRF), uma postagem de Laura compartilhada de Cristiane Bentes: 
Enquanto aguardava o cumprimento do alvará pude escutar o choro de algumas, os gritos de ordem dados pelos agentes federais, como se a ditadura tivesse voltado. [...] A comida é servida mas como comer sufocada de gás e esplay e pimenta? [...] O grito fora das mães que sufocam frente ao presídio podem socorro e imploram para que não agridem as suas filhas.

O relato une-se às várias denúncias que deixam as mulheres em situação de vulnerabilidade em tempos de negação dos direitos humanos. Depois vem a postagem de Cássia, com o compartilhamento de uma matéria sobre as falas do ministro Paulo Guedes sobre a primeira-dama francesa. No texto acima do compartilhamento, na postagem: " $E$ um menosprezo pela mulher tão grande que só me dá nojo. Falta de respeito, de postura, excesso de grosseria e arrogância".

No fluxo de acontecimentos, fica cada vez mais evidente o lugar da mulher para o atual governo, fazendo com que, nesse coletivo MUCB, as mulheres expressem que não têm nenhum valor para a política corrente: "Menosprezo", um afeto de abandono. Diante da fala do ministro, outro enunciado se destaca: "Nojo". É em torno de um olhar e de ações de desprezo pelo outro que a teoria queer, movimento importante no debate de gênero, emerge. Segundo Mayara Coelho (2016, p. 218), “a política e a teoria queer se instituíram na década de 1980, nos [Estados Unidos] EUA, juntamente ao surgimento de AIDS. O termo surge ligado a um movimento representativo de uma parte rejeitada, humilhada, considerada motivo de desprezo e nojo".

Agora, diante de representantes da política nacional que se apresentam sexistas, coletivos organizam-se em torno das questões de gênero, protagonizando acontecimentos em âmbito nacional, como temos vistos por parte do coletivo MUCB. O olhar de desprezo para falas como a de Paulo Guedes vem como mobilizador de ações que se efetivam na rede. As mobilizações potencializam-se numa "ecologia da ação" em rede, adquirindo um caráter "comunicativo da ação" (DI FELICE, 2013, p. 273).

No dia 15 de setembro alguns temas se repetem, como \#EleNão. Diferentemente dos outros dias analisados, algumas postagens mostram bons exemplos: "Engenheiro cego cria bengala que usa o Google Maps para ajudar pessoas cegas", "Mãe cria série inspirada para mostrar que não existe "coisa de menina". Entre as postagens com mais curtidas e comentários, está: "Jean Wyllys será professor em Harvard", compartilhado da página riogaylife.com.br. Nos comentários das postagens do dia 15, alguns assuntos acabam retornando: "Todo dia um homem branco hetero cis 60 mais falando merda, diminuindo mulheres, se 
achando na posição de julgar a beleza alheia e falando merda". Seguem vários comentários dessa natureza. O desprezo pelas falas do presidente Bolsonaro e do ministro da Economia Paulo Guedes, referindo-se ao caso da primeira-dama francesa, é mais recorrente e associado ao que se tem de mais desprezível na produção humana.

Outra postagem, "Homem estupra neta de 9 anos e avó culpa criança”, de Jéssica, em 15 de setembro, está entre as mais comentadas, sendo o enunciado "monstro" o que mais apareceu para qualificar a personagem que cometeu a ação. As postagens seguem nessa gangorra entre casos que expõem a vulnerabilidade de alguns diante da violência exercida por outros e ações que indicam amparo, esperança de que o mundo poderá ser diferente, como na postagem "Papa Francisco promove bispo pró-direitos [lésbicas, gays, bissexuais e transgênero] LGBT para cardeal no Vaticano", de 15 de setembro, matéria compartilhada da página razoesparaacreditar.com.

No dia 20 de setembro, destaca-se a postagem de Lane com mais curtidas e comentários no grupo do Facebook nesse recorte da pesquisa: "Casal de lésbicas é espancada após rejeitar se beijar para homens assistirem”. Novamente uma situação que expõe a vulnerabilidade das mulheres numa sociedade que se mostra conservadora e estimulada a praticar violência.

Nesse mesmo dia, Klaudinha compartilha matéria da revista Carta Capital: "Dilma Rousseff protagoniza filme sobre mulheres presas na ditadura". A violência contra mulheres dá o tom das postagens do dia 20: "Grupo gratuito de terapia para mulheres ajuda a sair de relação abusiva", "Mãe diz sofrer ameaça de expulsão por levar filha para Universidade", "[Conselho Federal de Medicina] CFM põe The Handmaid's Tale em prática ao determinar que um feto está acima de uma mulher", "Aluna se suicida após ser expulsa de aula por causa de menstruação". Além dos posts sobre violência contra as mulheres, outros temas são abordados, como racismo e homofobia.

Denúncias de violência contra a mulher na luta feminina ganham forma mais acentuada a partir dos anos de 1970, com as "feministas americanas denunciando a violência sexual" (BANDEIRA, 2014, p. 450). Expor a violência praticada constitui uma das dimensões de luta feminina e expandiu-se para a luta contra a violência de gênero. Com a onipresença da rede digital, as lutas potencializaram-se.

No dia 27 de setembro, o destaque inicia-se com uma nota oficial do MUCB (publicada no dia 26) sobre os ataques ao grupo no aplicativo Telegram ${ }^{6}$. A nota,

${ }^{6}$ Serviço de mensagens instantâneas baseado em computação em nuvem.

DOI: http://doi.org/10.14393/par-v6n1-2021-61066 - Paradoxos, Uberlândia, v. 6, n. 1, p. 103-123, jan./jun. 2021| 117 
postada por Ludimilla, comunica que "nosso grupo de administradores no Telegram acaba de ser atacado e deletado. SIM fomos hackeadas e tentaram calar a nossa!". Nesse dia, a predominância das postagens é quanto às ações de Bolsonaro e seu filho Eduardo. Entre elas, está o anúncio de mobilização em comemoração a um ano do \#EleNão: "Ele nem deveria ter entrado e já passou da hora de sair!"; "Bolsonaro tira sarro de desempregado que o admira: 'só pelo bafo não vai ter emprego",, compartilhado do Brasil 247; "Em discurso na ONU, Bolsonaro escancara programa ultradireita e anti-indígena", compartilhado do jornal El País; “Discurso de Bolsonaro 'rebaixa o país a uma república de bananas", da CBN.

Em relação a Eduardo Bolsonaro, ainda no dia 27 de setembro, o primeiro post, de Angela, foi o compartilhamento da postagem de Sergio, com uma foto em que o político faz gesto de arma com as duas mãos em frente ao monumento-símbolo do desarmamento na sede da ONU, em Nova York, nos Estados Unidos. Outra aparição foi a matéria compartilhada por Sueli do portal UOL: "Criticado por foto falsa de Greta, Eduardo integra [comissão parlamentar de inquérito] CPI das fake News". A ativista Greta Thunberg também aparece várias vezes. Em um dos posts, de Elaine, com matéria compartilhada da RFI Brasil: "Greta Thunberg não éfinanciada por George Soros”. Nos comentários, "vergonha, que volta a aparecer: ‘[...] Brasileiro acostumado a pedir desculpas pela vergonha alheia dos que são sem vergonha".

Em outro compartilhamento, postado por Altair, também no dia 27 de setembro, "A campanha de ódio, mentiras e desinformação contra a ativista Greta Thunberg", do Polígrafo, nos comentários encontramos: "Sou ambientalista e sei bem como nosso trabalho é árduo. Já fui seguida, já fui ameaçada e todos os dias, a gente tem uma mira apontada nas costas".

No dia 4 de outubro, o destaque inicial foi para a publicação de Ana, um longo texto que começa com: “Amamos mulheres! Desde que elas se depilem totalmente a ponto de parecerem crianças. Sim, vaginas 'infantis' são ovacionadas”. Um texto de militância em que teve repercussão o mesmo tom nos comentários: "Texto necessário", "se não for para ser simplesmente uma mulher do meи jeito, o que eи vou ser?" etc.

A temática LGBTQI+ também esteve presente nesse dia 4 de outubro. Em matéria publicada no Estadão e compartilhada por Isabelle há: "Primeira modelo transgênero da Victoria's Secret é brasileira". Nos comentários, palavras e frases de afirmação, como "maravilhosa", "já ganhou meu coração" etc. 
O ativismo na rede segue as lutas afirmativas de gênero, seja nas questões identitárias da mulher, seja na temática LGBTQI+, assim como via conteúdos transversais, como o do meio ambiente. No calor dos acontecimentos diários, esse ecossistema digital expande-se. O net-ativismo, portanto, acelera os "posicionamentos e defesas políticas, em prol de meio ambiente, de atitudes cidadãs via meios digitais, configurando uma comunicação que aproxima de uma livre expressão de uma criação compartilhada" (MATOS, 2019, p. 70).

O ministro da Educação à época, Abraham Weintraub, e o diretor também à época da Fundação Nacional de Artes (Funarte), Roberto Alvim, começam a ser pauta das postagens. O primeiro post, em 4 de outubro, de Celília, critica o ministro ao falar que salário de professor é uma "zebra borda". No segundo, Gilca compartilha uma matéria da Veja: "Diretor da Funarte decide entregar teatro no Rio a companhia evangélica". Nos comentários: "O que está acontecendo com este país? Quanta ignorância", "toma vergonha nessa sua cara de pau, seu vendido", "camisa de força" etc.

Em outra postagem do dia 4, Ione compartilha post da página Quebrando o Tabu: "A jogadora da seleção brasileira, Ludmilla, sendo perseguida dentro de um supermercado por se negra". Nos comentários, assim como em outros envolvendo racismo, aparecem depoimentos sobre acontecimentos semelhantes: "Já passei isso várias vezes, se for 'mal' vestida, não me pergunte o que é mal-vestida, eles fiam atrás". Novamente, o enunciado "vergonhoso".

Com grande repercussão, ainda no dia 4 de outubro, a postagem de Katia, "todo poder emana do povo", com o compartilhamento sobre levantes populares no Peru e no Equador. Nos comentários, o tom era de que agora precisaria o mesmo acontecer no Brasil: "Quero ver o levante aqui", "América do Sul desestabilizada", "Estamos esperando quando o Brasil vai acordar" etc.

Entre as publicações com maior repercussão em 18 de outubro, a notícia compartilhada por Ivanilda sobre o deputado federal Waldir Soares de Oliveira (PSL), conhecido como Delegado Waldir, com a declaração: "Nós somos Bolsonaro; somos como mulher traída, apanha e volta para o aconchego". Na descrição do post: "Em um tempo onde a violência doméstica está em alta e lutamos todos os dias para deter, dói na alma ouvir um deputado falando isso!!’. A comparação dos correligionários de Bolsonaro com a mulher traída é um exemplo claro de naturalização e reprodução dessas práticas, o 
que levou muitas mulheres a comentarem o post. Entre os comentários, alguns enunciados voltaram a se repetir, entre eles "nojento".

Ao contrário dos outros dias, em 18 de outubro a maior parte das postagens foi para mostrar ações do grupo e bons exemplo: "Festival Lula-livre- Santa Catarina", "Dia do professor - mensagem de Haddad e Ana Estela", "Casal gay adota bebê com HIV que foi rejeitado por 10 famílias: Olívia é perfeita", "Emma Watson lança consultório jurídico gratuito para mulheres assediadas no local de trabalho", "Steven Tyler inaugura instituto para acolher meninas vítimas de abuso", "Harvard diz que Einstein da nossa geração já nasceu, é mulher e tem 24 anos", "Absorventes ecológicos de alunos da [Faculdade de Educação Tecnológica do Estado do Rio de Janeiro] Faetec já tem pedido do exterior".

Nas postagens que expõem práticas racistas, homofóbicas ou sexistas, alguns enunciados: "horror", "nojo", "louca desiquilibrada" (em um post sobre a ministra da Mulher, da Família e dos Direitos Humanos Damares Alves), "ódio".

No último dia da pesquisa, 25 de outubro, entre as postagens mais curtidas e comentadas, o compartilhamento por Deisi da notícia da revista Fórum: "Rosa Weber vota contra prisão em segunda instância e pode tirar Lula da cadeia". As postagens mostradas em destaque pelo Facebook, em sua maioria, eram dedicadas a declarações de Bolsonaro, à descoberta da presença de óleo nas praias do nordeste e a projetos da base do governo. Em um post publicado no dia 18 de outubro, mas em destaque no dia 25 de Celília, o compartilhado de uma notícia do portal Catraca Livre: "Deputada do PSL pede fim do abordo [aborto] para mulheres que foram estupradas". O texto que antecede a notícia encerra-se com o comentário: "Cada argumento que fere qualquer ser humano com inteligência. Mais uma doida varrida vinda direto do PSL - Partido Só de Louco".

\section{Considerações}

Nesta pesquisa foi analisado como os laços sociais se organizam no grupo fechado do Facebook MUCB, com base nos recortes de gênero e da noção de desamparo como mobilizador do coletivo de mulheres. As postagens giram em torno do governo com ações e falas que ameaçam as várias formas de ser mulher. O ativismo na rede fez circular falas que questionam padrões dominantes de regulação da cultura, sobretudo no que se refere à sexualidade. Mas, como vimos, essas falas vão além. $\mathrm{O}$ descaso com a natureza e com 
a educação e a democracia em risco são alguns dos temas também recorrentes. A lista é grande, mas, para sintetizar, são manifestações contra o que coloca a vida em risco, principalmente a vida das mulheres.

Se as postagens sobre o governo atual são o carro-chefe, por outro lado várias publicações se referem às ações do grupo, exemplos de empoderamento, ou seja, um conjunto de manifestações que funcionam também como forma de amparo. Esse circuito de afetos desenvolve-se numa ecologia das redes, na qual são formadas interações humanas (entre os atores) e não humanas (inteligência artificial, algoritmos, big datas etc.).

Esta pesquisa fez funcionar um princípio constitutivo da subjetividade, a noção de desamparo, e como essa noção está articulada na vida política, ou seja, diante de práticas governamentais e de uma sociedade que se apresentam cada vez mais intolerantes com as múltiplas formas de viver. Formam-se, então, levantes, coletivos, como o MUCB, que protestam e, ao mesmo tempo, criam formas de amparo.

\section{Referências}

BABO, Isabel. Redes e ativismo. In: DI FELICE, Massimo; PEREIRA, Eliete; ROZA, Erick (org.). Net-ativismo: redes digitais e novas práticas de participação. Campinas: Papirus, 2017. p. 77-88.

BANDEIRA, Lourdes Maria. Violência de gênero: a construção de um campo teórico e de investigação. Sociedade e Estado, Brasília, v. 29, n. 2, p. 449-469, ago. 2014. Disponível em: http://www.scielo.br/scielo.php?script=sci_arttext\&pid=S010269922014000200008\&lng=en\&nrm=iso. Acesso em: 1. ${ }^{\circ}$ maio 2021. DOI: https://doi.org/10.1590/s0102-69922014000200008.

CASTELLS, Manuel. A galáxia da internet. Rio de Janeiro: Jorge Zahar, 2003.

COELHO, Mayara Pacheco. Vozes que ecoam: feminismo e mídias sociais. Pesquisa e Práticas Psicossociais, São João del-Rei, v. 11, n. 1, p. 214-224, jun. 2016. Disponível em: http://pepsic.bvsalud.org/scielo.php?script=sci_arttext\&pid=S180989082016000100017\&lng=pt\&nrm=iso. Acesso em: 29 abr. 2021.

DELEUZE, Gilles; GUATTARI, Félix. Mil platôs: capitalismo e esquizofrenia. São Paulo: 34, 1997. v. 1.

DI FELICE, Massimo. Net-ativismo e ecologia da ação em contextos reticulares. Contemporânea: Comunicação e Cultura, v. 11, n. 2, p. 267-283, maio-ago. 2013. DOI: https://doi.org/10.11606/d.27.2012.tde-20052013-151543. 
DI FELICE, Massimo. Ser redes: o formalismo digital dos movimentos net-ativismo. Matrizes, São Paulo, n. 7, p. 49-71, jul.-dez. 2015. Disponível em:

https://www.revistas.usp.br/matrizes/article/view/69406. Acesso em: 2 set. 2020.

EL PAÍS. Grupo "Mulheres contra Bolsonaro" no Facebook sofre ataque cibernético. El País, 19 set. 2018. Disponível em:

https://brasil.elpais.com/brasil/2018/09/14/politica/1536941007_569454.html. Acesso em: 27 abr. 2021.

ELY, Lara. As transformações das relações sociais em tempos de net-ativismo. Entrevista especial com Massimo Di Felice. Instituto Humanitas Unisinos, 2018. Disponível em: http://www.ihu.unisinos.br/159-noticias/entrevistas/575807-astransformacoes-das-relacoes-sociais-em-tempos-de-net-ativismo-entrevista-especialcom-massimo-di-felice. Acesso em: 28 dez. 2019.

FOUCAULT, Michel. Microfísica do poder. Rio de Janeiro: Graal, 1999.

FOUCAULT, Michel. O sujeito e o poder. In: DREYFUS, Hubert; RABINOW, Paul (org.). Michel Foucault: uma trajetória filosófica. Rio de Janeiro: Forense Universitária, 1985. p. 231-236.

FREUD, Sigmund. Inibição, sintoma e angústia. In: FREUD, Sigmund. Obras completas. São Paulo: Companhia das Letras, 2014. v. 17. p. 13-123.

FREUD, Sigmund. O futuro de uma ilusão (1927). In: FREUD, Sigmund. Edição standard brasileira das obras psicológicas completas de Sigmund Freud. vol. XXI. Rio de Janeiro: Imago, 1996. v. 21.

FREUD, Sigmund. Projeto para uma psicologia científica. In: FREUD, Sigmund. Edição standard brasileira das obras psicológicas completas de Sigmund Freud. Rio de Janeiro: Imago, 1990. v. 1. p. 385-529.

GOMES, Camila de Magalhães. Gênero como categoria de análise decolonial. Civitas, Porto Alegre, v. 18, n. 1, p. 65-82, jan.-abr. 2018. DOI: https://doi.org/10.15448/19847289.2018.1.28209.

MATOS, Silvio Simão. Subjetivação e ativismo nos canais DePretas e Louie Ponto: identificação, engajamento e pertencimento. 250f. Tese (Doutorado em Comunicação e Cultura) - Escola de Comunicação, Universidade Federal do Rio de Janeiro, Rio de Janeiro, 2019.

MATSUURA, Sérgio. Como o grupo Mulheres Contra Bolsonaro foi hackeado no Facebook. Época, 19 set. 2018. Disponível em: https://epoca.globo.com/como-grupomulheres-contra-bolsonaro-foi-hackeado-no-facebook-23083037. Acesso em: 27 abr. 2021.

PEDRO, Joana Maria. Narrativas fundadoras do feminismo: poderes e conflitos (19701978). Revista Brasileira de História, São Paulo, v. 26, n. 52, p. 249-272, 2006. DOI: https://doi.org/10.1590/s0102-01882006000200011. 
PELÚCIO, Larissa; PAZ, Diego. \#paslui: feminismos brasileiros no hexágono europeu. Revista Estudos Feministas, Florianópolis, v. 28, n. 3, e71498, 2020. DOI: https://doi.org/10.1590/1806-9584-2020v28n371498.

PINTO, Céli Regina Jardin. Uma história do feminismo no Brasil. São Paulo: Fundação Perseu Abramo, 2003.

RESSTEL, Cizina Célia Fernandes Pereira. Desamparo psíquico. In: Desamparo psíquico nos filhos de dekasseguis no retorno ao Brasil. São Paulo: Editora Unesp; São Paulo: Cultura Acadêmica, 2015. p. 8. DOI: https://doi.org/10.7476/9788579836749.

SAFATLE, Vladimir. Cinismo e falência da crítica. São Paulo: Boitempo, 2008.

SAFATLE, Vladimir. Freud como teórico da modernização bloqueada. A Peste, São Paulo, v. 1, n. 2, p. 355-374, jul./dez. 2009.

SAFATLE, Vladimir. O circuito dos afetos: corpos políticos, desamparo e o fim do indivíduo. São Paulo: Autêntica, 2016. DOI: https://doi.org/10.26512/rfmc.v3i1.12501.

SAFATLE, Vladimir. Por outros corpos políticos, individuais e coletivos. Revista Epos, Rio de Janeiro, v. 6, n. 2, p. 220-224, dez. 2015. Disponível em: http://pepsic.bvsalud.org/scielo.php?script=sci arttext\&pid=S2178700X2015000200012\&lng=pt\&nrm=iso. Acesso em: 2 set. 2020.

SARTI, Cynthia A. Feminismo no Brasil: uma trajetória particular. Cadernos de Pesquisa, n. 64, p. 38-47, 2013.

SCOTT, Joan W. Gênero: uma categoria útil de análise histórica. Educação e Realidade, v. 15, n. 2, p. 5-22, 1990.

VENERA, José I. Por uma teoria do sujeito intervalar na experiência com a tela escura. $R U A$, v. 25, n. 2, p. 505-521, 21 nov. 2019. DOI:

https://doi.org/10.20396/rua.v25i2.8657559. 